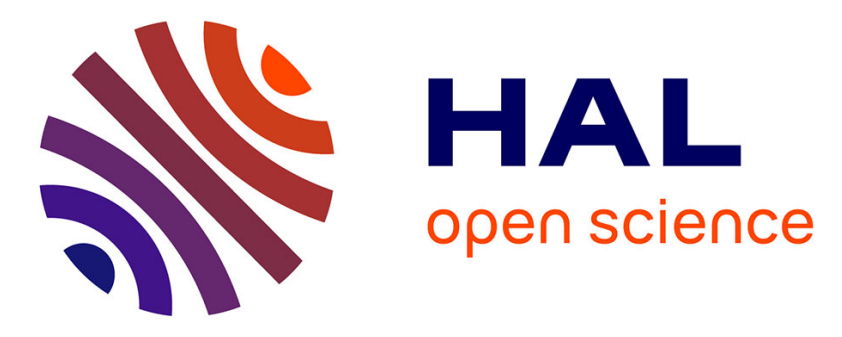

\title{
Adsorption of Magnetic Nanoparticles onto Polyacrylamide Chains in Dilute Polymer Solutions and "Ferrogel" Networks
}

Delphine El Kharrat, Olivier Sandre, Pedro Licinio, Régine Perzynski

\section{To cite this version:}

Delphine El Kharrat, Olivier Sandre, Pedro Licinio, Régine Perzynski. Adsorption of Magnetic Nanoparticles onto Polyacrylamide Chains in Dilute Polymer Solutions and "Ferrogel" Networks. The 3rd International Symposium on Slow Dynamics in Complex Systems, Nov 2003, Sendai, Japan. pp.122-123, 10.1063/1.1764084 . hal-00174166

\author{
HAL Id: hal-00174166 \\ https://hal.science/hal-00174166
}

Submitted on 27 May 2019

HAL is a multi-disciplinary open access archive for the deposit and dissemination of scientific research documents, whether they are published or not. The documents may come from teaching and research institutions in France or abroad, or from public or private research centers.
L'archive ouverte pluridisciplinaire HAL, est destinée au dépôt et à la diffusion de documents scientifiques de niveau recherche, publiés ou non, émanant des établissements d'enseignement et de recherche français ou étrangers, des laboratoires publics ou privés. 


\title{
Adsorption of Magnetic Nanoparticles onto Polyacrylamide Chains in Dilute Polymer Solutions and Ferrogel Networks
}

\author{
Delphine El kharrat*, Olivier Sandre*, Pedro Licinio* ${ }^{\dagger}$, and Régine Perzynski ${ }^{\dagger}$ \\ *Laboratoire Liquides Ioniques et Interfaces Chargées UMR7612 Centre National de la Recherche Scientifique \\ ${ }^{\dagger}$ Laboratoire Milieux Désordonnés et Hétérogènes UMR7603 Centre National de la Recherche Scientifique \\ / Université Pierre et Marie Curie - 4, place Jussieu *case 63 / $^{\dagger}$ case 78, 75252 Paris cedex 05 , France
}

\begin{abstract}
We study iron oxide nanoparticles stabilized by citrate ligands interacting with long linear poly(acrylamide) chains in the regime where the diluted chains are decorated by many smaller magnetic nanoparticles. The strength of adsorption of the particles onto polymer increases when the unbound citrate concentration decreases, as evidenced by the faster translational dynamics of the particle-polymer complexes and the slower rotational dynamics of the nanoparticles.
\end{abstract}

\section{INTRODUCTION}

A novel class of nanocomposite materials called "ferrogels" with possible applications as magnetic actuators can be obtained by embedding magnetic nanoparticles in a soft polymer matrix highly swollen by water [1]. In a previous work, we have studied such magnetic hydrogels made of the combination of a poly(acryamide) hydrogel cross-linked by N,N'methylene-bis-acrylamide and an aqueous "citrated ferrofluid" [2]. The latter is a suspension of iron oxide nanoparticles in water at $\mathrm{pH} \approx 7$ stabilized by surface charges provided by citrate ligands in equilibrium with unbound tri-sodium citrate electrolyte. We found that the swelling degree $\mathrm{Q}$ of these ferrogels (defined as the amount of absorbed water per dry polymer weight) is lower for ferrogels compared to undoped hydrogels. In addition, Q presents a minimum value as a function of salinity at low citrate salt concentration. To understand this specific role of the citrate ligands on the polymerparticle interactions, we study here a somehow simpler system consisting of linear poly(acrylamide) chains having a calculated radius of gyration in water around $100 \mathrm{~nm}$ mixed with the same magnetic nanoparticles in different citrate buffers. The resulting mixtures are fluid and can be studied by different dynamical methods: macroscopic viscosimetry, dynamic light scattering and oscillatory magneto-birefringence in cross-fields, the latter probing the micro-rhelogy in the local environment of the nanoparticles [3].

\section{MATERALS}

We used a commercial poly(acrylamide) (PAM) homopolymer (Polysciences) known as to strongly interact with metal oxide colloids. This very long linear PAM $\left(5-6 \times 10^{6} \mathrm{~g} / \mathrm{mol}\right)$ is commonly used as a flocculent. As for the magnetic nanoparticles, they came from ionic ferrofluids prepared by alkaline coprecipitation of $\mathrm{FeCl}_{2}$ and $\mathrm{FeCl}_{3}$ followed by complete oxidation using $\mathrm{Fe}\left(\mathrm{NO}_{3}\right)_{3}$ leading to positively charged $\gamma-\mathrm{Fe}_{2} \mathrm{O}_{3}$ (maghemite) nanoparticles in $\mathrm{HNO}_{3}(\mathrm{pH}=1.2)$. A size-sorting process yielded a fraction of narrower distribution of diameters, described by a Log-normal law of parameters $d_{0}=6.6 \mathrm{~nm}$ and $\sigma=0.21$. Finally the iron oxide surface was coated by tri-sodium citrate ligands leading to a stable dispersion of negatively charged nanoparticles at $\mathrm{pH}=7.2$.

After complete dissolution in tri-sodium citrate of the polymer at a concentration $0.6 \mathrm{~g} / \mathrm{L}$ lower than $\mathrm{c}^{*}$ (which is estimated about $2.4 \mathrm{~g} / \mathrm{L}$ ), the citrated ferrofluid was introduced in the solutions and allowed to equilibrate overnight. Two values of the final salt concentration $\left[\mathrm{Na}_{3} \mathrm{Cit}\right]$ were examined, respectively a low concentration $(8 \mathrm{mM})$ and a larger one $(50 \mathrm{mM})$. The volume ratio of the nanoparticles relatively to the polymer was kept at a constant value $(=2)$ all along the dilutions required for the viscosimetry experiment. 
TABLE 1. Intrinsic viscosity $\lceil\eta]\left(\mathrm{g}^{-1} \cdot \mathrm{mL}\right)$ measured by capillary viscosimetry for PAM $\left(5-6 \times 10^{6}\right)$ solutions mixed with 2 volume equivalents of citrated ferrofluid.

\begin{tabular}{lcc}
\hline [sodium citrate] $=$ & $\mathbf{5 0 m M}$ & $\mathbf{8 m M}$ \\
\hline Polymer only & 535 & 595 \\
Polymer + particles & 495 & 435
\end{tabular}

\section{RESULTS}

Capillary viscosimetry shows that the conformation of chains with and without nanoparticles does not vary a lot at high citrate concentration ( $8 \%$ decrease at $50 \mathrm{mM}$ citrate), whereas the presence of nanoparticles decreases the chain swelling significantly when the citrate concentration is lower $(27 \%$ decrease at $8 \mathrm{mM})$. The same effect of lowering the citrate concentration on the shrinking of the polymer chains by the nanoparticles is also observed by dynamical light scattering, the hydrodynamic diameter of the polymerferrofluid complexes varying from $\mathrm{d}_{\mathrm{H}}=107 \mathrm{~nm}$ at $50 \mathrm{mM}$ of unbound citrate down to $\mathrm{d}_{\mathrm{H}}=78 \mathrm{~nm}$ at $8 \mathrm{mM}$.

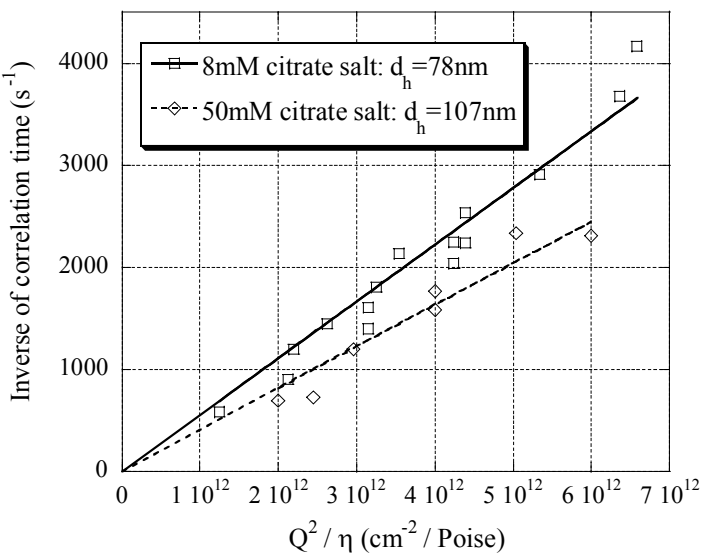

FIGURE 1. Dynamic light scattering: the hydrodynamic diameters of the polymer-particles complexes at the two citrate salt concentrations are measured from the slope of the main relaxation rate (from CONTIN fit of the correlogram) $v s$. the square of wave vector divided by viscosity.

With cross-fields magneto-birefrengence we get the frequency response of nanoparticles rotation in their local environment. In the presence of polymer, the visco-elastic behavior is evidenced by the phase shift at low frequency, increasing when $\left[\mathrm{Na}_{3} \mathrm{Cit}\right]$ decreases. Therefore we can conclude that the nanoparticles strongly interact with the long linear poly(acrylamide) chains and that this coupling becomes stronger at lower unbound citrate salt concentration in equlibrium with the citrate ligands. An adsorption of the particles onto the chains is thus very probable, for it explains the specific effect of the citrate concentration by a competition between the citrate ligands and the polar amide groups of the polymer to access the surface of iron oxide. In the case of complete adsorption, we calculate that on average $10^{2}$ particles can adsorb on a single chain. Having proved that the polymer-particles complexes behave as microgels swelling and shrinking in a similar way as cross-linked ferrogels, we showed by AFM that they also exhibit a necklace morphology.

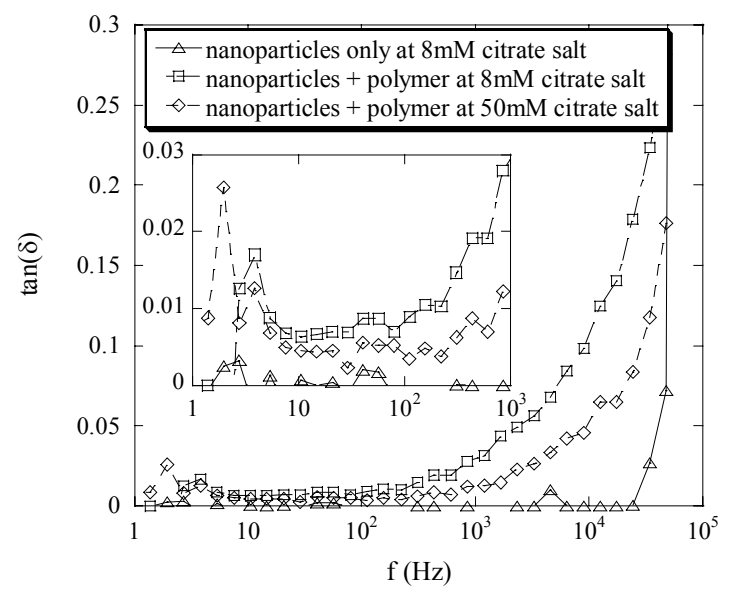

FIGURE 2. Cross-fields dynamical birefringence: the non zero phase shift angle between the magnetically induced birefringence and the ac $\mathrm{H}$ field is a sign of visco-elasticity.

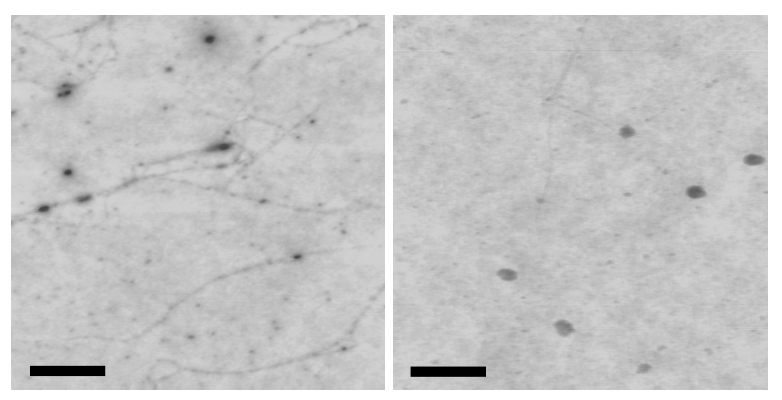

FIGURE 3. AFM pictures of PAM solutions mixed with 2 vol. of citrated ferrofluid deposited on mica at $8 \mathrm{mM}$ (left) and $50 \mathrm{mM}$ citrate (right, scale bars $=500 \mathrm{~nm}$ ). Necklaces of spheres about $80 \mathrm{~nm}$ in diameter linked to rigid segments up to $1 \mu \mathrm{m}$ long are thought to be particles-shielded polymers.

\section{REFERENCES}

1. Zrínyi, M., Barsi, L., and Büki, A., J. Chem. Phys. 104, 8750-8756 (1996)

2. Galicia, A. Sandre, O. Cousin, F. Guemghar, D. Ménager, C., and Cabuil, V., J. Phys. Cond. Mat. 15, S1379-S1402 (2003).

3. Hasmonay, E. Dubois, E. Neveu, S. Bacri, J.-C., and Perzynski, R., Eur. Phys. J. B 21, 19-29 (2001). 